\title{
Mood changes and the dark focus of accommodation
}

\author{
R. J. MILLER \\ Washington State University, Pullman, Washington 99164
}

\begin{abstract}
The consistency of dark focus of accommodation (the refractive power of the eye in total darkness) and its relationship to mood were examined. Twenty-one subjects were tested over a 2- to 3-week period using a laser optometer and several standard mood measures (including the Multiple Affect Adjective Check List). It was found that dark focus was reasonably consistent in most subjects over that period. Furthermore, correlations between dark focus and mood were related to dark focus variability; that is, higher dark focus-mood correlations and higher scores on several mood measures were most apt to be found among subjects with higher session-to-session dark focus variability. It was concluded that dark focus is a fairly stable phenomenon. It may also prove to be a promising technique for investigating mood changes, particularly for subjects whose dark focus variability is high, although more research is required.
\end{abstract}

Dark focus of accommodation refers to the refractive power of the eye in the absence of an external stimulus for accommodation, as is the case, for example, in total darkness. Research has shown that as illumination is decreased, accommodation shifts from a focus that is more or less appropriate to the actual distance of the stimulus to an intermediate dark focus (Alpern \& David, 1958; Campbell \& Primrose, 1953; Johnson, 1976; Leibowitz, Hennessy, \& Owens, 1975; Leibowitz \& Owens, 1975a; Otero, 1951; Owens \& Leibowitz, 1975; Wald \& Griffin, 1947). Shifts toward the dark focus point also occur when the subject looks through a small artificial pupil, thereby increasing the depth of field and rendering accommodation unnecessary (Hennessy, Iida, Shiina, \& Leibowitz, 1976; Leibowitz et al., 1975; Leibowitz \& Owens, 1975b), as well as when the subject is looking into a bright field containing no contours or texture (i.e., a Ganzfeld) (Leibowitz \& Owens, 1975b; Luckiesh \& Moss, 1940; Westheimer, 1957; Whiteside, 1952). It appears that whenever the 'visual field becomes impoverished in terms of specific stimuli for accommodation, or when accommodation has no influence on the quality of the retinal image, the accommodation response shifts toward dark focus.

Leibowitz and Owens (1975b), who examined a sample of 124 college-age subjects, reported that the mean dark focus was 1.71 diopters (D) ${ }^{1}$ (corresponding to a focal distance of $58.5 \mathrm{~cm})$. The standard deviation was 0.72 . There were fairly wide individual

The author expresses his appreciation to Herschel W. Leibowitz, Carole Clements, Maria Jungel, George Leary, and Harold Dengerink for their assistance. Reprint requests should be addressed to R. J. Miller, 350 Johnson Tower, Department of Psychology, Washington State University, Pullman, Washington 99164. differences, ranging from 0 to $4 \mathrm{D}$. Thus, each individual appears to have a characteristic dark focus. This dark focus serves as a reference point for the accommodation response in the absence of clear visual information for accommodation or when accommodation is unnecessary for a clear image. Indeed, some research indicates that the dark focus response influences accommodation in the viewing of even highly contoured, well-illuminated stimuli, producing a certain degree of overaccommodation for far objects and underaccommodation for near objects (Johnson, 1976; Leibowitz \& Owens, 1975a). Dark focus apparently also accounts to a considerable degree for various anomalous myopias, including night myopia (Leibowitz \& Owens, 1975a, 1975b; Owens \& Leibowitz, 1976), empty field or Ganzfeld myopia (Leibowitz \& Owens, 1975b), and instrument myopia (Hennessy, 1975), and for the paradoxical variation of visual acuity with viewing distance (Johnson, 1976).

It would appear, then, that dark focus is a factor of considerable importance in perceiving the world. Given such a factor, it would be useful to answer some basic questions regarding its characteristics. The present research effort was directed toward answering some of these questions.

The first question has to do with the consistency of dark focus. Is an individual's dark focus a consistent "trait," maintaining the same value over an extended period of time, or does it shift from day to day or week to week? Most past studies have reported a limited number of dark focus measurements, usually not extending over more than a day or two of time. The only exceptions are 8-day baselines reported for three subjects by Leibowitz (1976). One purpose of the present research effort was to examine a larger 
number of subjects over a long enough period of time to gather reliable data concerning the day-to-day variability of dark focus.

The second question grows out of the first. If an individual's dark focus does vary, what is the source or reason for such variability? One could, no doubt, generate many hypotheses, but one candidate appears to be variation in emotion or stress. There are several reasons for suspecting stress. It is widely accepted that the ciliary muscles, responsible for accommodation, are autonomically innervated. The exact nature of this innervation is unclear; while it used to be thought that the ciliary muscles were affected solely by parasympathetic impulses, there is now some evidence that the sympathetic division also plays a part, although what part is still ambiguous (Alpern, 1969; Brown, 1965; Davson, 1972; Schober, 1954). At any rate, the presence of autonomic innervation, in general, and sympathetic involvement, in particular, would make it logical to suspect that stress might have an influence. Evidence from several sources (Cogan, 1937; Olmstead, 1944; Toates, 1972; Westheimer, 1957) suggests that accommodation is affected by stress and emotion. Clinical reports and a few empirical studies have linked visual acuity (a process at least partly influenced by accommodation) with stress levels and a variety of personality characteristics (e.g., Kelley, 1962; Lanyon \& Giddings, 1974; Palmer, 1966; Young, 1967; Young, Singer, \& Foster, 1975). Leibowitz (1976) relates descriptions of two cases where a change in dark focus occurred during the same time that the subjects were under unusual stress. In addition, Hess (1975) has shown that pupil size, which is mediated by some of the same neuromuscular systems as accommodation, reflects changes in emotion, interest, and attitudes. The second purpose of the present project, then, was to investigate whether dark focus was related to emotion or mood, both on an intrasubject basis (the degree to which individual variability in dark focus is reflected in mood variability), and on an intersubject basis (the degree to which characteristic dark focus "traits" are related to general overall mood levels).

\section{METHOD}

\section{Apparatus}

Dark focus was measured with a laser optometer, various stages and refinements in the development and use of which have been reported by several researchers (Hennessy \& Leibowitz, 1970, 1972; Ingelstam \& Ragnarsson, 1972, Knoll, 1966; Leibowitz \& Hennessy, 1975; Mohon \& Rodemann, 1973). The apparatus used in the present project was very similar to one described by Owens and Leibowitz (1975).

The laser optometer is diagrammed in Figure 1. A beam of light from a low-output laser ( $2.5 \mathrm{mw}$ He-Ne, Metrologic ML920) was diverged with a $+20-\mathrm{D}$ lens and then reflected from the surface of a slowly revolving drum $(0.63 \mathrm{rpm}$, diameter $=6.60 \mathrm{~cm})$. The refiected laser pattern was then superimposed in the subject's visual field. In the present study, all subjects viewed the reflected pattern monocularly, with the left eye. The right eye was neither covered nor closed. The subjects were not instructed to look at anything in particular, but rather were told just to relax and look ahead. The room was completely dark and the laser and apparatus were masked off so that absolutely no light was visible to the subject except when the laser pattern was exposed, and then only the laser pattern was visible. The reflected pattern was seen by the subject as a speckled pattern, the perceived movement of which was determined by the movement of the drum and the subject's state of accommodation. If the subject was accommodated to a point closer than the optical distance of the drum, the speckles were perceived as moving in the same direction as the drum's rotation. If the subject was accommodated beyond the optical distance of the drum, the speckles appeared to move in a direction opposite to the drum's rotation. When the drum was at the optical distance to which the subject was accommodated, the speckles appeared to swirl randomly or remain stationary. The speckle pattern itself has no effect on accommodation, as demonstrated by Leibowitz and Owens (1975a), who showed that such patterns, even for long intervals of exposure, do not affect accommodation, and by Hennessy and Leibowitz (1970) in experiments showing that a test flash duration of $0.5 \mathrm{sec}$ (the exposure duration used in the present study) does not affect accommodation.

A +5-D lens was inserted into the path of the laser pattern, between the subject and the drum, at a distance of one focal length $(20 \mathrm{~cm})$ from the eye of the subject. The optical distance of the drum (which slid along an optical bench) could be varied from infinity (zero diopters) to $20 \mathrm{~cm}(+5 \mathrm{D})$ without changing the apparent size or brightness of the speckle pattern (the Badal principle-see Hennessy \& Leibowitz, 1972; Ogle, 1968), although the actual distance of the drum from the subject's eye varied over a range of only $20 \mathrm{~cm}$.

Mood was assessed using two paper-and-pencil inventories. One was the Multiple Affect Adjective Check List (MAACL) developed by Zuckerman and his colleagues (Zuckerman, 1960; Zuckerman, Lubin, Vogel, \& Valerius, 1964). The MAACL is comprised of a list of 89 adjectives, each one reflecting one of three emotional states-anxiety, depression, or hostility. Each subject was given the list (the adjectives were in random order) with instructions to indicate how he or she felt by checking each of the words that pertained to his or her mood "at the present time." The subject was then given a score on each of the three emotional states, depending on which adjectives were checked.

In the present study, it was deemed desirable to have, in addition to the traditional scores on each of the three emotional states, an overall score reflecting the subject's performance on the test as a whole. As a result, the subject's three scores were com-

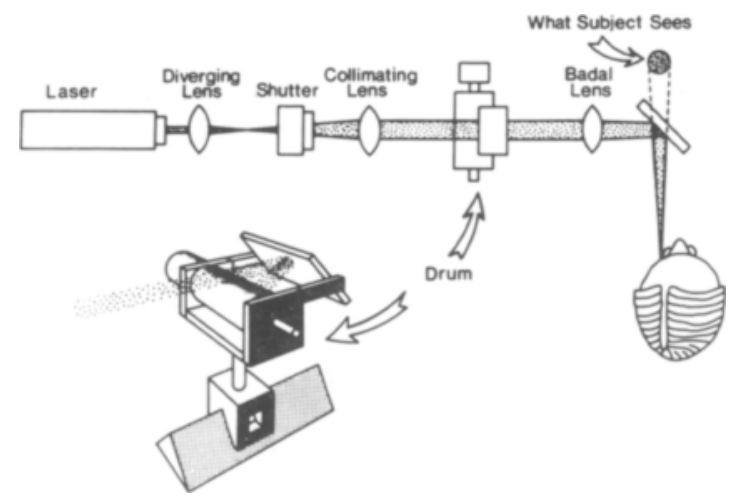

Figure 1. Schematic diagram of the laser optomer. 
bined for a single total score. It was not sufficient simply to sum the scores on the three moods, since they were based on unequal numbers of adjectives. To compensate for this inequality, the scores were weighted in proportion to their corresponding numbers of adjectives. The final score was determined according to the following formula: Total score $=(.4762 \times$ Anxiety score $)+(.250$ $\times$ Depression score $)+(.3571 \times$ Hostility score $)$. This total score was assumed to indicate an overall degree of stress or negative mood.

The anxiety, depression, and hostility scales were originally empirically constructed. Zuckerman and his colleagues (Zuckerman, 1960; Zuckerman et al., 1964) reported that scores on these three scales were related to other measures of mood and also reflected experimentally induced emotional changes; thus they have concurrent and construct validity. The total combined score was developed for the present project and has no reliability or validity data available, although its intuitive appeal is obvious.

In addition to the MAACL, a second mood scale was administered. This was a very simple list of 10 descriptive phrases ranging from "complete elation, rapturous joy, and soaring ecstasy" at one end of the scale (i.e., No. 1) to "utter depression and gloom. Completely down. All is black and leaden. Wish it were all over" at the other end of the scale (i.e., No. 10). This procedure was reported by Wessman, Ricks, and Tyl (1960) and will be referred to as the WRT mood scale in the present report. The subject's task was to indicate which of the 10 descriptions best described his or her mood "at the present moment." The score was the number preceding the statement chosen. Thus, the higher the score, the more negative the mood. Since this was only a 10-point scale, it was not expected to be as sensitive as the MAACL, and was included mainly out of curiosity, although it is quick and easy to use and would be useful in future research if it could be shown to have predictive validity with regard to dark focus. It was hoped that it might also help substantiate the validity of the total score on the MAACL.

\section{Subjects}

Subjects were 21 undergraduate volunteers ( 14 females and 7 males) recruited from introductory courses in psychology at Washington State University. They were reimbursed for their participation by the awarding of credits in their psychology classes. Subjects were not required to meet any particular criteria for visual acuity, although if they had corrective lenses they were required to wear them for all sessions. One subject's data were rejected because she reported a history of strabismus and a resulting deficit in her left eye.

\section{Procedure}

The subjects were asked to report to the laboratory twice a day (once in the morning and once in the evening), 2 days per week, for 3 weeks (a total of 12 sessions). Of the 2 days per week, one of the days was a Monday or Wednesday and the other was a Tuesday or Thursday. Most students' Monday-Wednesday schedules were different from their Tuesday-Thursday schedules, and it was desired to sample as wide a variety of experiences as possible. In some cases, the 3 weeks were consecutive, and in some cases vacations intervened, but this was not considered a difficulty because, again, a wide variety of subject experiences was desired. Each subject reported to one practice session before beginning the 3-week measurement period to become familiar with the apparatus and procedures. Although not all subjects made it to all 12 sessions, all subjects were able to complete at least 5 complete days of measurements (i.e., 10 sessions). Sixteen of the 21 subjects did complete all 12 sessions.

For each session, the procedure was the same. The subject was first asked to fill out the MAACL and the WRT mood scale. The subject was then briefly questioned regarding any unusual life stresses, any physical discomforts he or she might be experiencing, and to make certain that the subject was not under the influence of any drugs. The subjects were cautioned from the beginning of the study not to take any drugs or medications on test days unless absolutely essential.

After the mood scales and questioning were completed, the subject sat down at the optometer and a head-and-chin rest was adjusted to place the speckled pattern in the subject's line of vision. Then the lights were extinguished and the subject's dark focus was measured. All dark focus measurements were conducted in a totally dark room. The subject sat in the position indicated in Figure 1, the left eye located at a distance of $20 \mathrm{~cm}$ from the Badal lens. A "bracketing" technique was then used to find the dark focus point. The speckled pattern was flashed for $.50 \mathrm{sec}$ at irregular intervals. After each exposure, the subject indicated the perceived direction of motion of the speckled pattern (up or down). The drum was then moved to a different position on the optical bench. At the beginning of each series of presentations, the drum was located at extreme near and far optical distances (thus "bracketing" the dark focus point). With succeeding presentations, the distance between near and far flashes was gradually reduced, $1 \mathrm{~cm}$ at a time, until the point of no apparent motion was found.

This value was recorded as the dark focus point, with two corrections added. "Since laser light is monochromatic, a small constant compensating for axial chromatic aberration of the eye (+.33 D, assuming $560 \mathrm{~nm}$ as the reference wavelength) must be added to each measure to obtain the absolute accommodation" (Owens \& Leibowitz, 1975). In addition, the apparatus was set up so that the optical distance of the dark focus point was measured to the surface of the drum. Charman (1974) has shown that for this type of apparatus, using a drum rather than a flat surface for reflection, the effective plane of stationarity is actually at a point between the surface of the drum and its center. Using Charman's formula, this plane was found to lie $1.99 \mathrm{~cm}$ from the drum's surface, and this correction was also included in the final conversion.

Each session consisted of the subject's going through this series of presentations of the speckled pattern three times in succession. The mean of the three series was then taken as the dark focus measure for that session. During some series, the drum rotated in a clockwise direction, and in other series, it rotated in the opposite direction. Direction of rotation was determined randomly and was never, of course, changed during a series of presentations -only at the beginning of the series. This random change in direction was used as a control to prevent the subject from anticipating the direction of motion of the speckle pattern.

\section{RESULTS}

\section{Consistency}

Mean dark focus across all sessions was calculated for each subject. These means are shown in Table 1 . The mean of these means was $2.76 \mathrm{D}(\mathrm{SD}=1.24)$. Most subjects did not vary a great deal from day to day in dark focus, the mean intrasubject range being $1.10 \mathrm{D}$ (mean intrasubject SD $=.36$ ). Only 3 of the 21 subjects $(14.3 \%)$ had a range of more than $1.5 \mathrm{D}$, the maximum range being $2.92 \mathrm{D}(\mathrm{SD}=1.09)$. As a further measure of variability, the test-retest reliability of the dark focus measure was calculated. The first session's measurement for each subject was correlated with the second session's measurement, yielding a Pearson product-moment $r$ of $\mathbf{. 9 4 8 . ~ A d d i t i o n a l l y , ~}$ each subject's first session measurement was compared with the measurement from the last session, 
Table 1

Basic Data for All Measures

\begin{tabular}{|c|c|c|c|c|c|c|c|c|c|c|c|c|c|}
\hline \multirow{2}{*}{$\begin{array}{c}\text { Subject } \\
\text { No. }\end{array}$} & \multirow[b]{2}{*}{ Sex } & \multicolumn{2}{|c|}{$\mathbf{d f} \mathbf{f}^{\mathbf{a}}$} & \multicolumn{2}{|c|}{$\begin{array}{l}\text { MAACL } \\
\text { Anxiety }\end{array}$} & \multicolumn{2}{|c|}{$\begin{array}{c}\text { MAACL } \\
\text { Depression }\end{array}$} & \multicolumn{2}{|c|}{$\begin{array}{l}\text { MAACL } \\
\text { Hostility }\end{array}$} & \multicolumn{2}{|c|}{$\begin{array}{c}\text { MAACL } \\
\text { Total }\end{array}$} & \multicolumn{2}{|c|}{ WRT } \\
\hline & & $\overline{\mathbf{x}}$ & SD & $\overline{\mathbf{X}}$ & $\mathrm{r}^{\mathrm{b}}$ & $\overline{\mathbf{x}}$ & $\mathrm{r}^{\mathrm{b}}$ & $\overline{\mathrm{x}}$ & $\mathrm{r}^{\mathrm{b}}$ & $\overline{\mathbf{x}}$ & $\mathbf{r}^{\mathbf{b}}$ & $\overline{\mathbf{x}}$ & $\mathbf{r}^{\mathbf{b}}$ \\
\hline $\begin{array}{l}1 \\
2 \\
3 \\
4 \\
5\end{array}$ & $\begin{array}{l}\mathbf{F} \\
\mathbf{M} \\
\mathbf{F} \\
\mathbf{F} \\
\mathbf{F}\end{array}$ & $\begin{array}{l}3.05 \\
2.76 \\
3.68 \\
3.31 \\
2.11\end{array}$ & $\begin{array}{r}1.09 \\
.73 \\
.52 \\
.49 \\
.45\end{array}$ & $\begin{array}{r}12.50 \\
9.90 \\
7.20 \\
9.92 \\
5.83\end{array}$ & $\begin{array}{r}.280 \\
.808 \\
-.076 \\
.279 \\
-.142\end{array}$ & $\begin{array}{r}21.00 \\
16.60 \\
17.30 \\
17.50 \\
9.58\end{array}$ & $\begin{array}{r}.345 \\
.644 \\
-.194 \\
.004 \\
.128\end{array}$ & $\begin{array}{r}12.58 \\
11.40 \\
9.30 \\
9.17 \\
6.58\end{array}$ & $\begin{array}{r}.460 \\
.430 \\
.110 \\
.026 \\
-.025\end{array}$ & $\begin{array}{r}15.70 \\
12.94 \\
11.07 \\
12.37 \\
7.53\end{array}$ & $\begin{array}{r}.424 \\
.701 \\
-.020 \\
.157 \\
-.001\end{array}$ & $\begin{array}{l}5.42 \\
4.90 \\
5.10 \\
4.83 \\
4.08\end{array}$ & $\begin{array}{r}.570 \\
.346 \\
.264 \\
-.271 \\
.260\end{array}$ \\
\hline $\begin{array}{r}6 \\
7 \\
8 \\
9 \\
10\end{array}$ & $\begin{array}{l}\mathbf{M} \\
\mathbf{F} \\
\mathbf{F} \\
\mathbf{M} \\
\mathbf{M}\end{array}$ & $\begin{array}{l}2.24 \\
4.12 \\
4.15 \\
2.21 \\
4.31\end{array}$ & $\begin{array}{l}.44 \\
.42 \\
.36 \\
.32 \\
.32\end{array}$ & $\begin{array}{l}8.50 \\
4.70 \\
8.58 \\
8.30 \\
7.80\end{array}$ & $\begin{array}{r}-.040 \\
.223 \\
-.362 \\
.927 \\
.072\end{array}$ & $\begin{array}{l}19.17 \\
14.60 \\
15.83 \\
18.10 \\
15.30\end{array}$ & $\begin{array}{r}.068 \\
-.141 \\
.057 \\
.880 \\
.427\end{array}$ & $\begin{array}{r}10.83 \\
8.10 \\
9.58 \\
9.60 \\
8.90\end{array}$ & $\begin{array}{r}.058 \\
-.023 \\
.014 \\
.766 \\
-.133\end{array}$ & $\begin{array}{r}12.71 \\
8.78 \\
11.47 \\
11.91 \\
10.72\end{array}$ & $\begin{array}{r}.017 \\
.002 \\
-.113 \\
.895 \\
.199\end{array}$ & $\begin{array}{l}4.50 \\
4.40 \\
4.58 \\
5.30 \\
4.90\end{array}$ & $\begin{array}{r}.032 \\
-.144 \\
-.197 \\
.912 \\
.297\end{array}$ \\
\hline $\begin{array}{l}11 \\
12 \\
13 \\
14 \\
15\end{array}$ & $\begin{array}{l}\mathbf{M} \\
\mathrm{F} \\
\mathbf{F} \\
\mathbf{F} \\
\mathbf{F}\end{array}$ & $\begin{array}{l}0.97 \\
4.27 \\
2.32 \\
1.78 \\
4.21\end{array}$ & $\begin{array}{l}.30 \\
.29 \\
.26 \\
.26 \\
.25\end{array}$ & $\begin{array}{l}9.67 \\
1.83 \\
8.00 \\
6.92 \\
6.08\end{array}$ & $\begin{array}{r}.493 \\
-.081 \\
-.203 \\
-.314 \\
-.011\end{array}$ & $\begin{array}{r}17.83 \\
5.00 \\
18.42 \\
17.33 \\
11.75\end{array}$ & $\begin{array}{r}.225 \\
-.135 \\
.032 \\
-.329 \\
.097\end{array}$ & $\begin{array}{r}8.67 \\
3.33 \\
10.58 \\
10.42 \\
6.17\end{array}$ & $\begin{array}{r}.053 \\
-.161 \\
.402 \\
.072 \\
.119\end{array}$ & $\begin{array}{r}12.16 \\
3.31 \\
12.19 \\
11.35 \\
8.04\end{array}$ & $\begin{array}{r}.284 \\
-.127 \\
.075 \\
-.219 \\
.059\end{array}$ & $\begin{array}{l}5.08 \\
4.33 \\
4.75 \\
4.17 \\
4.58\end{array}$ & $\begin{array}{r}.146 \\
-.163 \\
-.055 \\
-.335 \\
.219\end{array}$ \\
\hline $\begin{array}{l}16 \\
17 \\
18 \\
19 \\
20\end{array}$ & $\begin{array}{l}\mathbf{F} \\
\mathbf{M} \\
\mathbf{F} \\
\mathbf{M} \\
\mathbf{F}\end{array}$ & $\begin{array}{l}1.18 \\
2.61 \\
0.39 \\
1.19 \\
2.70\end{array}$ & $\begin{array}{l}.22 \\
.20 \\
.19 \\
.18 \\
.18\end{array}$ & $\begin{array}{l}7.00 \\
8.08 \\
9.25 \\
6.08 \\
7.42\end{array}$ & $\begin{array}{r}-.044 \\
-.590 \\
-.099 \\
.182 \\
-.394\end{array}$ & $\begin{array}{l}14.08 \\
15.42 \\
14.83 \\
14.17 \\
14.08\end{array}$ & $\begin{array}{r}.033 \\
-.537 \\
-.112 \\
-.072 \\
-.385\end{array}$ & $\begin{array}{r}7.17 \\
12.00 \\
7.67 \\
6.33 \\
9.75\end{array}$ & $\begin{array}{r}.010 \\
-.256 \\
-.216 \\
-.049 \\
.111\end{array}$ & $\begin{array}{r}9.50 \\
11.99 \\
10.85 \\
8.70 \\
10.54\end{array}$ & $\begin{array}{r}.039 \\
-.450 \\
-.166 \\
.026 \\
-.346\end{array}$ & $\begin{array}{l}4.75 \\
5.00 \\
4.83 \\
4.58 \\
4.67\end{array}$ & $\begin{array}{r}.494 \\
-.285 \\
-.079 \\
.508 \\
-.291\end{array}$ \\
\hline 21 & $\mathbf{F}$ & 4.45 & .02 & 8.25 & .040 & 15.75 & -.021 & 9.08 & .217 & 11.11 & .092 & 4.33 & .391 \\
\hline
\end{tabular}

${ }^{a}$ Dark focus data. Means given in diopters. Subjects arranged in order of decreasing standard deviation. ${ }^{\mathrm{b}}$ Intrasubject correlations between session-to-session scores on this measure and corresponding df measures.

Table 2

Mood Measures and Their Relationship to Dark Focus

\begin{tabular}{|c|c|c|c|c|c|c|}
\hline Mood Measures & $1^{a}$ & $2^{b}$ & $3^{c}$ & $4^{d}$ & $5^{\mathbf{e}}$ & $6^{f}$ \\
\hline $\begin{array}{l}\text { MAACL Total } \\
\text { MAACL Anxiety } \\
\text { MAACL Depression } \\
\text { MAACL Hostility } \\
\text { WRT }\end{array}$ & $\begin{array}{r}10.71 \\
7.71 \\
15.41 \\
8.91 \\
4.72\end{array}$ & $\begin{array}{l}.073 \\
.045 \\
.048 \\
.095 \\
.125\end{array}$ & $\begin{array}{l}.473^{* *} \\
.390^{*} \\
.418^{*} \\
.391^{*} \\
.234\end{array}$ & $\begin{array}{l}-.196 \\
-.247 \\
-.212 \\
-.058 \\
-.140\end{array}$ & $\begin{array}{l}.452^{* *} \\
.472^{* *} \\
.370^{*} \\
.420^{*} \\
.437^{* *}\end{array}$ & $\begin{array}{r}-.036 \\
.067 \\
-.087 \\
-.007 \\
-.188\end{array}$ \\
\hline
\end{tabular}

${ }^{a}$ Mean of all subjects across all sessions on the mood scales. b $_{\text {Mean }}$ of subjects' correlations of dark focus with mood scale scores. 'Correlations between standard deviations of subjects' dark focus measurements and those subjects' dark focus-mood correlations. 'Correlations between subjects' mean dark focus measurements and mean mood scores. 'Correlations between standard deviations of subjects' dark focus measurements and those subjects' mean mood scores. 'Correlations between standard deviations of subjects' dark focus measurements and standard deviations of those subjects' mood measurements.

${ }^{*} p<.05(d f=19$, one-tailed).

${ }^{* *} p<.025(d f=19$, one-tailed $)$

demonstrating a Pearson $r$ of .852. The amount of time that elapsed between the first and second sessions varied from 7.5 to $12.5 \mathrm{~h}$, and the time between the first and last sessions varied from 14 to 24 days, so the measure showed both short- and long-term reliability.

\section{Mood}

For each session in which he or she participated, each subject had a dark focus (DF) measure and five mood measures (MAACL Total, MAACL Anxiety, MAACL Depression, MAACL Hostility, and WRT). In an attempt to determine if dark focus was related to mood, correlation coefficients were calculated for the relationship between each subject's 10 or 12 dark focus measurements and his or her corresponding scores on each of the mood scales. If dark focus reflects mood, one might expect to find significant correlations between mood and dark focus. That is, when a subject's dark focus changes, one would expect mood to change correspondingly. Positive correlations would indicate that higher mood scores (i.e., higher anxiety, depression, etc.) were accompanied by closer dark focus; negative correlations would indicate dark focus going furthel out with increases in mood scores. Table 2 , column 2 , shows the results of these correlations. It is clear that none of these means is very high. 
It was not true, however, that dark focus was unpredictive of mood for all subjects. Inspection of the data made it clear that the low correlations between mood and dark focus were most characteristic of subjects whose session-to-session dark focus variability was low--since their dark focus did not change much from session to session, it could not be correlated with anything. However, for subjects whose dark focus variability was greater, the correlations between dark focus and mood were more likely to be higher. Column 3 of Table 2 shows correlations between intrasubject variability (i.e., the standard deviation of each subject's 10-12 dark focus measurements) and the corresponding dark focus-mood correlation for each subject. As noted in Table 2, all of these correlations are statistically significant, except for that involving the WRT. In other words, the higher the variability of a subject's dark focus, the greater the likelihood that the subject's dark focus changes reflected mood changes.

While dark focus variability was related to dark focus-mood correlations, it was not related to the amount of mood variability. Correlations between intrasubject dark focus standard deviations and intrasubject standard deviations of all the mood measures are shown in column 6 of Table 2. None of these correlations was statistically significant. The fact that a subject showed wide mood variability did not necessarily mean that the subject also demonstrated wide dark focus variability.

Another way of examining the relationship between dark focus and mood is to ask if such relationships hold across subjects as well as from session to session for the individual subject. That is, are subjects whose characteristic dark focus is close likely to show different overall moods than subjects with far dark focus points? One way of examining this question is to look at the correlations between subjects' overall mean dark focus and their overall mood scores. These correlation coefficients are shown in column 4 of Table 2. It is clear that they are not very high for any of the mood measures. Knowing a subject's average dark focus will not let us predict average mood level. However, variability again emerges as a possible predictor. Those subjects with high sessionto-session dark focus variability tended to have higher scores on most of the mood measures than did subjects with little such variability. Table 2 , column 5 , shows the correlations between intrasubject dark focus variability (i.e., the standard deviation of the subject's 10-12 dark focus measurements) and each subject's mean mood scores (across all sessions). All of the correlation coefficients are statistically significant, as indicated in Table 2. This appears to indicate that subjects with relatively highly variable dark focus were more anxious, hostile, etc., than subjects who had a relatively invariant dark focus.

\section{Diurnal Variation}

Since both morning and evening data were available, a logical question was whether there were any consistent differences in dark focus as a function of the time of day in which measurements were taken. Mean morning and evening dark focus measures were compared for all subjects, and the difference between the two time periods was not statistically significant $[\mathrm{t}(20)=-1.28, \mathrm{p}>.10]$. However, dark focus variability again emerged as an important variable. Comparing mean morning and evening dark focus scores for the seven subjects in thesupper one-third of the dark focus variability distribution (see Table 1) yielded a significant difference $[\mathrm{t}(6)=$ $-3.03, p<.05]$. For all of these subjects, mean evening dark focus scores were higher (indicating closer dark focus) than were their corresponding morning scores. The difference between morning and evening measures for the seven subjects in the lower one-third of the dark focus variability distribution was not significant $[\mathrm{t}(6)=1.89, \mathrm{p}>.10]$. All statistical tests for the morning-evening comparisons were two-tailed.

A Pearson product-moment correlation coefficient was calculated with subjects' session-to-session dark focus variability (i.e., the standard deviations across sessions) as one variable and the absolute mean amount of morning-to-evening change in dark focus for each subject (ignoring direction of change) as the other variable. The resulting coefficient was .777 $[\mathrm{t}(19)=5.38, \mathrm{p}<.01]$. This result, while hardly surprising, confirms the observation that as session-tosession variability increased, so did the degree of morning-to-evening variability.

\section{DISCUSSION AND CONCLUSIONS}

The present study was an attempt to answer two questions-how consistent is dark focus of accommodation and, to the extent that it varies, is that variability related to changes in stress, mood, emotion, etc.?

In reply to the first question, it must be concluded that dark focus is fairly consistent. The majority of the subjects in this study did not vary more than 1.0 D over the course of the 2 to 3 weeks of measurement. This finding is reasonably consistent with the view that dark focus is traitlike in nature. That is, most people appear to have a characteristic dark focus point that may be quite different from that of other individuals, but is fairly consistent over time -at least over the time periods examined in the present study. There does seem to be some diurnal variation in dark focus, particularly for subjects whose dark focus variability is in the upper end of the distribution. Whether this is related to fatigue, 
biorhythmic variables, or other factors awaits future research.

Regarding the second question, it appears that the dark focus of accommodation may bear some relationship to mood. The relationship is not overwhelming in magnitude, however, and the key seems to be variability in dark focus rather than the location of the dark focus point per se. That is, subjects who showed relatively high session-to-session variability in dark focus were more likely than low-variability subjects to demonstrate meaningful positive correlations between dark focus changes and mood changes. Their dark focus points more often tended to move closer to them as their anxiety, depression, etc., increased. Further, a similar trend was seen on an intersubject basis. High-variability subjects tended to have higher average day-to-day mood scores (higher anxiety, depression, hostility, etc.) than did lowvariability subjects. Such relationships were certainly not characteristic of all subjects, however, as is apparent in Table 1, and must at present be regarded as no more than suggestive. Obviously, more research is required.

These findings have several implications. For one thing, they provide some support for the position that the ciliary body has autonomic innervation, and further, through this innervation is responsive to the general stress response sequence of the autonomic nervous system. For another, these results suggest that further exploration of the possible relationship between mood and dark focus might well be worthwhile. Dark focus may have the potential of becoming another useful technique in the armamentarium of peripheral physiological assessment.

\section{REFERENCES}

AlPERN, M. Accommodation. In H. Davson (Ed.), The eye (Vol. 3; 2nd ed.) Muscular mechanisms. New York: Academic Press, 1969.

AlPERN, M., \& DAVID, H. Effects of illuminance quantity on accommodation of the eyes. Industrial Medicine and Surgery, 1958, 27, 551-555.

BROwN, J. L. The structure of the visual system. In C. H. Graham (Ed.), Vision and visual perception. New York: Wiley, 1965.

Campbell, F. W., \& Primrose, J. A. E. The state of accommodation of the human eye in darkness. Transactions of the Ophthalmological Society of the United Kingdom, 1953, 73, 353-361.

Charman, $W$. N. On the position of the plane of stationarity in laser refraction. American Journal of Optometry and Physiological Optics, 1974, 51, 832-838.

CogAN, D. G. Accommodation and the autonomic nervous system. Archives of Ophthalmology, 1937, 18, 739-766.

Davson, H. The physiology of the eye (3rd ed.). New York: Academic Press, 1972.

HenNessy, R. T. Instrument myopia. Journal of the Optical Society of America, 1975, 65, 1114-1120.

Hennessy, R. T., Iida, T., Shina, K., \& Leibowitz, H. W. The effects of pupil size on accommodation. Vision Research, 1976, $16,587.589$.

Hennessy, R. T., \& Leibowitz, H. W. Subjective measurement of accommodation with laser light. Journal of the Optical Society of America, 1970, 60, 1700-1701.

Hennessy, R. T., \& Leibowitz, H. W. Laser optometer incorporating the Badal principle. Behavior Research Methods \& Instrumentation, 1972, 4, 237-239.

Hess, E. H. The tell-tale eye. New York: Van Nostrand Reinhold, 1975.

Ingelstam, E., \& Ragnarsson, S.-I. Eye refraction examined by aid of speckle pattern produced by coherent light. Vision Research, 1972, 12, 411-420.

Jownson, C. A. Effects of luminance and stimulus distance on accommodation and visual resolution. Journal of the Optical Society of America, 1976, 66, 138-142.

KELLEY, C. R. Psychological factors in myopia. Journal of the American Optometric Association, 1962, 33, 833-837.

KNoLL, H. A. Measuring ametropia with a gas laser: A preliminary report. American Journal of Optometry, 1966, 43, 415-418.

Lanyon, R. I., \& Giddrngs, J. W. Psychological approaches to myopia: A review. American Journal of Optometry and Physiological Optics, 1974, 51, 271-281.

LeIBowITz, H. W. Visual perception and stress. In G. Borg (Ed.), Physical work and effort, New York: Pergamon Press, 1976.

LEIBowitz, H. W., \& Hennessy, R. T. The laser optometer and some implications for behavioral research. American Psychologist, 1975, 30, 349-352.

Leibowtiz, H. W., Hennessy, R. T., \& Owens, D. A. The intermediate resting position of accommodation and some implications for space perception. Psychologia, 1975, 18, 162-170.

Leibowitz, H. W., \& OwENs, D. A. Night myopia and the intermediate dark focus of accommodation. Journal of the Optical Society of America, 1975, 65, 1121-1128. (a)

Leibowitz, H. W., \& Owens, D. A. Anomalous myopias and the intermediate dark focus of accommodation. Science, 1975,189 , 646-648. (b)

Luckiesh, M., \& Moss, F. K. Functional adaptation to near vision. Joumal of Experimental Psychology, 1940, 26, 352-356.

Mohon, N., \& RodemanN, A. Laser speckle for determining ametropia and accommodation response of the eye. Applied Optics, 1973, 12, 783-787.

OGLE, K. N. Optics: An introduction for ophthalmologists (2nd ed.). Springfield, Ill: Thomas, 1968.

Otmste AD, J. M. D. The role of the autonomic nervous system in accommodation for far and near vision. Journal of Nervous and Mental Disease, 1944, 99, 794-798.

OTERO, J. M. Influence of the state of accommodation on the visual performance of the human eye. Journal of the Optical Society of America, 1951, 41, 942-948.

Owens, D. A., \& Leibowitz, H. W. The fixation point as a stimulus for accommodation. Vision Research, 1975, 15, 1161-1163.

Owens, D. A., \& Leibowitz, H. W. Night myopia: Cause and possible basis for amelioration. American Journal of Optometry and Physiological Optics, 1976, 53, 709-717.

Palmer, R. D. Visual acuity and excitement. Psychosomatic Medicine, 1966, 28 (4, pt. 1), 364-374.

SchoBER, H. [On the resting position of accommodation.] Optik, 1954, 11, 282-290.

ToATES, F. M. Accommodation function of the human eye. Physiological Reviews, 1972, 52, 828-863.

WALD, G., \& GRIFFIN, D. R. The change in refractive power of the human eye in dim and bright light. Journal of the Optical Society of America, 1947, 37, 321-336.

Wessman, A. E., Ricks, D. F., \& TyL, M. Characteristics and concomitants of mood fluctuation in college women. Journal of Abnormal and Social Psychology, 1960, 60, 117-126.

WeSTHEIMER, G. Accommodation measurements in empty visual fields. Joumal of the Optical Society of America, 1957, 47. 714-718.

Whiteside, T. C. D. Accommodation of the human eye in a bright 
and empty visual field. Journal of Physiology (London), $1952,118,65 \mathrm{P}$

Young, F. A. Myopia and personality. American Journal of Optometry and Archives of the American Academy of Optometry, 1967, 44, 192-201.

Young, F. A., Singer, R. M., \& Foster, D. The psychological differentiation of male myopes and non-myopes. American Journal of Optometry and Physiological Optics, 1975, 52, 679-686.

ZuCKERMAN, $M$. The development of an affect adjective check list for the measurement of anxiety. Journal of Consulting Psychology, 1960, 24, 457-462.

Zuckerman, M., Lubin, B., Vogel, L., \& Valerius, E. Measurement of experimentally induced affects. Joumal of Consulting Psychology, 1964, 28, 418-425.
NOTE

1. To give readers who have little experience with optics some idea of the biological significance of a diopter, it should be pointed out that in clinical practice the smallest unit typically used is $0.25 \mathrm{D}$. Changes in glasses prescriptions are not usually made unless they are at least 0.25 or $0.50 \mathrm{D}$.

(Received for publication June 19, 1978; accepted August 31, 1978.) 